\title{
Hans Bellmer e sua pequena anatomia da imagem: corpo próprio e psicanálise
}

\author{
Renata Damiano Riguinia* (1) \\ Cristina Moreira Marcos ${ }^{\mathrm{b}}$ (1) \\ aPontifícia Universidade Católica de Minas Gerais, Programa de Pós-Graduação em Psicologia, Belo Horizonte, MG, Brasil \\ bontifícia Universidade Católica de Minas Gerais, Programa de Pós-Graduação em Psicologia, \\ Programa Pesquisador Mineiro, Fundação de Amparo à Pesquisa do Estado de Minas Gerais, Belo Horizonte, MG, Brasil
}

Resumo: Em Petite Anatomie de l'image (1949), o artista Hans Bellmer formula uma teoria da imagem do corpo que parte da premissa de que a anatomia humana é subjetiva, imaginária e até permeada por estados psicopatológicos. Assim, Bellmer mostra um corpo interno desenhado por traços de memória e por uma imagem puramente psíquica, ou seja, ele coloca em cena o corpo pulsional. Diante dessa obra, perguntamos o que o artista ensina à psicanálise lacaniana sobre o corpo próprio e sua representação, conceitos importantes para a clínica. Nesse sentido, uma indicação valiosa orientará esta discussão: o segredo da imagem é a castração.

Palavras-chave: imagem, corpo próprio, gozo, castração.

\section{Introdução}

Quero revelar escandalosamente o interior que sempre se manterá oculto e é percebido por trás das sucessivas capas de uma estrutura humana e suas desconhecidas perdas.

(Bellmer, 1949)

Neste artigo, buscaremos elucidar questões, estabelecidas desde o campo da psicanálise, a respeito da imagem do corpo próprio e suas incidências na clínica. Para tanto, seguiremos um pequeno livro, Petite Anatomie de l'Image, escrito pelo artista Hans Bellmer entre os anos 1936-1949. O artista formula uma teoria da imagem do corpo partindo da ideia de que a anatomia humana é puramente subjetiva, imaginária e de que se alimenta de estados febris e psicopatológicos (Bellmer, 1949/2002). Ao buscar traçar uma forma psíquica da imagem, Bellmer nos mostra um corpo interno, desenhado por traços de memória e pela tessitura de uma imagem puramente psíquica que coloca em cena o gozo. Em outra via, Lacan, desde o início de seu ensino, afirma a importância da imagem do corpo próprio na formação do eu e seu lugar na relação com o psiquismo. Seguindo o percurso lacaniano sobre a imagem do corpo próprio, Miller (2005) nos mostra que "todas as análises sugeridas por Lacan do campo visual convergem para um ponto: em todos os casos, o segredo da imagem é a castração" (p. 322). $\mathrm{O}$ espaço entre esta formulação e o que se resgata do

* Endereço para correspondência: rriguini@gmail.com

1 Este trabalho foi realizado com apoio da Coordenação de Aperfeiçoamento de Pessoal de Nível Superior (Capes). Código de financiamento 001. saber bellmeriano sobre a imagem do corpo nos permite interrogar as diferentes relações com o corpo próprio como um índice clínico precioso.

No campo entre psicanálise e arte, seguimos a via aberta por Lacan que, essencialmente, se afasta da psicologia para se reintroduzir em uma problemática do objeto. Ou seja, o problema da arte coloca o problema do objeto e a relação que o sujeito mantém com este (Marcos, 2015; Wajcman, 1984). Com Bellmer, longe de buscarmos o sentido escamoteado de alguma perversão do artista encenada na obra, tentamos estabelecer o que está colocado, o que podemos ver sobre esse corpo representado na obra que é tomado como um objeto. Vale lembrar ainda, à guisa de introdução, que, a partir das elucidações de Lacan no Seminário $11^{2}$, Brousse (2001) pôde afirmar que "a arte da pintura não é senão representação do corpo" (p. 11). Ainda para esta autora, a obra de arte, tomada como sintoma, ensina à psicanálise a maneira pela qual o inconsciente se refere ao corpo na contemporaneidade ${ }^{3}$. Assim, nos perguntamos: o que nos ensina Hans Bellmer e sua Pequena anatomia da imagem sobre a imagem do corpo próprio?

Adiantamos: Hans Bellmer chamou de anatomia da imagem o que, em seu ensaio, pôde articular sobre o corpo e sua representação. Sabemos que a anatomia humana é um campo da biologia que se dispõe a estudar a forma e a estrutura do organismo humano, bem como

2 Neste Seminário (1964/1998), Lacan analisa os quadros Os embaixadores (1533), de Hans Holbein, e As meninas (1656), do pintor espanhol Diego Velásquez. Para Miller (2005), ali Lacan introduz uma novidade ao arrancar o campo escópico das contemplações do desejo encontrando, assim, o -phi da castração.

3 O que chamamos aqui de contemporaneidade é uma época profundamente marcada pelas duas Grandes Guerras, organizada pelo discurso da ciência sobre o corpo e vivida com um modo de gozo capitalista. 
de suas partes. Palavra de origem grega, ana quer dizer parte, e tomnei, cortar. Sua técnica principal é a dissecação, prática em que os cortes feitos na unidade permitem que as partes, isoladas, sejam mais bem examinadas. No entanto o pequeno livro do artista, publicado em 1949, vem, na fronteira entre ciência e arte, discutir sobre esta particular anatomia, que não incide sobre uma unidade corporal composta por suas partes, mas parte do corpo informe que ganha as mais diversas e impensáveis formas.

\section{Um pouco sobre $o$ artista}

Hans Bellmer (1902-1975) foi um artista plástico nascido em Kattowitz, Alemanha, cidade que, depois da Primeira Guerra Mundial, passa a pertencer à Polônia e se torna Katowice. Bellmer fugiu do nazismo e foi radicado na França, onde esteve às margens do surrealismo. $\mathrm{O}$ artista frequentou o grupo de Breton para em seguida engrossar o grupo dos dissidentes desse movimento ao lado de Georges Bataille, Michel Leiris, entre outros. Na França, foi reconhecido como ilustrador e pornógrafo logo que trabalhou na segunda edição da História do olho, de Georges Bataille, em 1947. No entanto sua jornada artística começa antes, ainda na Alemanha nazista, e tem uma relação de oposição a este sistema.

Hans Bellmer se destaca entre os artistas de sua época por exibir uma obra cuja unidade e consistência são consideradas únicas. Para Webb e Short (2004), tal unidade se dá na medida em que os trabalhos gráficos do artista complementam seus escritos. No trabalho de Bellmer, é difícil distinguir "a mão que escreve a serviço da mão que desenha" (Webb \& Short, 2004, p. 100) e discernir quando seus desenhos são deslocamentos e demonstração visual das ideias expressas pela escrita. Entre vários trabalhos, destacamos aqui o livro chamado Petite anatomie de l'image (1949). Este livro foi escolhido porque nele Bellmer elucida questões a respeito do corpo próprio e da imagem, conceitos valiosos à clínica.

\section{Hans Bellmer e o Surrealismo}

Em Petite anatomie de l'Image, Bellmer se aproxima do Manifesto Surrealista escrito por Andre Breton em 1924. Ambos os ensaios são, simultaneamente, um tratado sobre o irracional e um exemplo da fecundidade desse irracionalismo. Como Breton, influenciado pela psicanálise, Bellmer está ocupado com os efeitos determinantes do inconsciente na imaginação. Para Webb e Short (2004), os dois artistas iluminam o trajeto entre consciência e inconsciente, além de expor e tentar eliminar os agentes de repressão e vigilância que desligam certas conexões entre percepção e representação, objeto e imagem, consciência e sonho. Assim como Breton acreditava que uma escrita automática seria capaz de trazer à luz a obscura vida inconsciente, Bellmer trazia em seus desenhos e fotografias imagens dos recônditos subterrâneos da vida pulsional. Nesse sentido, o ensaio bellmeriano traz contribuições preciosas sobre o poder de provocação - seja de horror ou prazer - de uma imagem.

Vale acrescentar que Breton, ao tentar liberar o inconsciente nas manifestações automáticas, buscava encontrar algo da ordem do puro, do espontâneo, do primitivo, como se esse acesso permitisse representações inéditas e belas. No entanto o que o surrealismo traz é bem diferente. Para Foster (2008), o automatismo não foi libertador, já que descentrava radicalmente o sujeito em relação ao inconsciente e, nesse movimento, o que encontrava não era o uniforme e unitariamente belo, a boa forma, o autêntico e o singular, mas algo estritamente codificado, mecânico e consistente. Ou seja, ao deixar que o inconsciente viesse à superfície, o que se manifesta é a compulsão à repetição, o estranho ${ }^{4}$, a pulsão de morte. Os surrealistas dissidentes estavam bem à vontade com essa dimensão, enquanto Breton e os artistas à sua volta ainda se ancoravam no idealismo de um bom encontro com as pulsões sexuais, um encontro que não permitiria a contaminação da pulsão de morte.

Apesar de fazer parte do movimento surrealista, Bellmer, portanto, dele se afasta e se mantém à margem. Especialmente o erotismo bellmeriano, "erotismo sepulcral" (Foster, 2008, p. 186), se distancia das propostas de Breton. Tal erotismo se aproxima muito mais do de Georges Bataille. É um erotismo comparável ao suplício, pois carece da perda, essencialmente da perda da imagem como representação da boa forma. Para esses dois surrealistas, o homem erótico não pode ser todo, ele precisa deixar cair o envoltório do corpo, sua imagem. Assim, o grupo que reunia os chamados surrealistas dissidentes ${ }^{5}$ estava empenhado especialmente em explorar as possibilidades expressivas que a subversão dos princípios do antropomorfismo e suas implicações permitiam (Riguini, 2015). Essa fragmentação da anatomia ganha maior relevância no movimento surrealista quando este questiona o princípio de identidade. Ademais, não devemos nos espantar que

4 Aqui nos referimos à noção de estranho conforme o texto freudiano "O estranho", de 1919.

5 O grupo de artistas surrealistas estava reunido em torno de uma figura: Andre Breton. Georges Bataille foi uma figura controversa dentro do movimento e, tendo sido afastado, levou alguns representantes dele consigo. A diferença entre os surrealistas bretonianos e os dissidentes começa entre suas eróticas. Os primeiros concebem a fusão dos amantes como ponto de partida para criação. Para Bataille, principal representante do grupo dissidente, o que é enfatizado no encontro amoroso ou erótico é, ao contrário, seu poder e seu caráter destrutivo, em que o corpo agonizante, sacrificial, ganha relevo. Outra diferença importante é que, para os surrealistas, a poesia é um procedimento de totalização do sentido, convergindo poesia e alquimia, privilegiando a analogia como chave de interpretação do mundo. Busca-se uma linguagem perdida, o casamento das antinomias, a analogia universal, é a volta de certo idealismo. Vale enfatizar aqui, com Surya (2002), que, para Bataille, o idealismo era um grande inimigo. Tal discurso é irreconhecível para ele, principalmente tendo sob seus olhos a realidade fragmentária da guerra. Longe de qualquer ideal universalizante ou identificável a qualquer forma, Georges Bataille vai "pelo contrário, afirmar que o universo a nada se assemelha e nada mais é que informe, equivale a dizer que o universo é qualquer coisa como uma aranha ou um escarro" (Bataille, 1929, p. 382). 
o homem esteja dilacerado no período entre guerras. De fato, a geração à qual pertenceu Bellmer foi marcada pelos tumultos, inquietações e horrores das duas Grandes Guerras. O trabalho desses artistas está profundamente ligado a essa experiência.

Para os surrealistas dissidentes, revirar o mundo representativo é também questionar as garantias da existência. Ora, o homem ingênuo, ou o iludido, foi levado a acreditar que a figura humana, em sua unidade, é a testemunha mais confiável da experiência de si mesmo (Didi-Hubberman, 2002). O corpo constituiria a realidade biológica e unitária capaz de trazer conforto à subjetividade, ao contrário do abismo que pode se abrir na sua experiência interior, incalculável e desmedida. Ao entender a forma figurativa como assassinato de outras formas, estes artistas propõem colocar a forma a trabalho e, na sua decomposição, encontrar novas formas. Este trabalho entende a forma como uma violência operativa. Claro, ao mesmo tempo em que os autores falam de objetos artísticos, falam do corpo, da decomposição, do antropocentrismo e do corpo humano.

Abalar o mundo figurativo significa colocar em questão as garantias da existência. $\mathrm{O}$ naif crê que a figura é a experiência mais segura que o homem tem de si mesmo, e não ousa negar tal certeza, ainda que ele duvide de suas experiências anteriores. Ele imagina que, em relação ao que há de sem fundo na experiência interior, a experiência direta de seu corpo constitui a unidade biológica mais certa. Seu corpo, este instrumento de toda experiência espacial, lhe parece uma máquina segura, que ele representa por ela as coisas mais duráveis e mais vivas, seus deuses e seus mortos. (Einstein, 1929, p. 147)

Por mais paradoxal que pareça, Bataille deixará claro que a arte não abrirá caminho para humanização, mas para uma "desarquiteturização", uma desumanização que parte da forma do homem. Isso porque, para ele, "os homens não representam, aparentemente, no processo morfológico, mais que uma etapa intermediária entre os macacos e os grandes edifícios" (Bataille, 1929, p. 117). Ao que parece, é uma desarquiteturização visada na empreitada bellmeriana. Ou seja, desarquiteturizar as funções civilizadas de cada uma das partes do corpo a fim de trazer de volta a significação escamoteada, por ser violenta ou traumática (Riguini, 2015).

\section{0 trabalho entre escrita e desenho}

O ensaio que aqui tratamos começou a ser escrito em 1939, mas só foi concluído em 1949. Para Webb e Short (2004), a Pequena anatomia da imagem - texto e desenhos - é uma expressão da luta constante de Bellmer contra toda e qualquer "forma constituída, contra a realidade convencionalmente percebida e representada" (p. 103). O livro é a maior e melhor explanação das intenções que sustentam o trabalho pictorial de Bellmer, e elucida os processos mentais que determinam as formas criadas por ele. Ali, o artista dá uma explicação fisiológica e estrutural das fontes da metáfora e da analogia. O corpo, nessa perspectiva, é a base de um sistema estruturado, chamado inconsciente físico. Para Bellmer há, no corpo, um sistema arraigado que é tingido pelas sensações físicas e pelo erotismo. Segundo Webb e Short (2004), o argumento de Bellmer aponta que é do esforço em satisfazer as necessidades físicas que provém a energia que motiva toda construção de conhecimento, via certas operações com a linguagem. O corpo, para Bellmer, funciona como um anagrama, sua imagem é construída como imagem poética.

Em uma carta à amiga Polly (Bellmer, 1964, citado por Gonzalez 2007) Hans Bellmer, "com nervos em frangalhos" (p. 1), escreve sobre o projeto empreendido no livro. Publicado originalmente com título duplo Pequena anatomia do inconsciente físico ou a anatomia da imagem - Bellmer pontua que o duplo título indica seu duplo propósito. Primeiro ele pretende mostrar a existência de uma anatomia do corpo - inconsciente físico - "puramente subjetiva, imaginária" (p. 1) e, assim, esta anatomia se nutre de estados febris e psicopatológicos, onde estão incluídos os delírios sexuais. Quanto à anatomia da imagem, esta busca descrever "os processos e as coordenadas da imagem" (p. 1), que se ligam às expressões do corpo humano. Este mecanismo é comparável, para Bellmer, ao processo de formação da imagem poética.

O conhecimento deste sistema de conexões entre corpo e mente poderia explicar porque certas imagens, que parecem, todavia, irracionais, nos atinge como inexplicavelmente autêntico e ainda capaz de provocar aquele senso de perturbação que os surrealistas chamam de convulsiva. (Webb \& Short, 2004, p. 105)

Com “precisão cirúrgica", Bellmer apresenta uma anatomia fantástica. Assim como Freud pôde revelar uma psique assolada por conflitos pulsionais, Bellmer apresenta um corpo animado pelo sonho e capaz das mais diversas metamorfoses que possam ser determinadas pelo desejo. Webb e Short (2004) esclarecem que Bellmer tinha uma visão da vida humana muitas vezes pessimista. Ele entendia que nunca estaremos em paz ou contentes com o corpo próprio, já que somos criaturas feitas de impulsos que não encontram calma ou satisfação.

$\mathrm{Na}$ arte de Bellmer, o objeto é o corpo, e o corpo é um anagrama de infinitas possibilidades, articulável como uma frase. Bellmer busca no corpo, em seus orifícios e pelos contornos esfumaçados dos traços de seus desenhos, o lugar onde isso fala. O corpo, para Bellmer, é, antes de tudo, um corpo de prazer e gozo. Ele busca escapar de seus contornos, uma forma de ultrapassar os interditos e o próprio destino anatômico, como sugere Masson (2000). 


\section{Imagem 1}

Se Bellmer é um artista que usou vários instrumentos para se exprimir - desenhos, fotografias, esculturas e escritos - os conteúdos e temas de sua obra, no entanto, não eram variáveis. Desde os primeiros trabalhos, é sobre o corpo feminino que incidem as técnicas bellmerianas.

Em Bellmer, o corpo, sempre o feminino, traz incontáveis possibilidades de integração e desintegração a partir do qual o desejo forma a imagem do desejo. Contudo "podemos prever uma deriva desses sonhos interanatômicos na consciência e na consciência coletiva, de onde se segue que os aspectos do sex-appeal feminino se encontram às portas de ricas vias de aplicação na moda, na estética, nas relações entre os sexos e nas cartas de amor" (Bellmer, 1949/2002, p. 48). O que Bellmer propõe é desarticular o corpo-imagem, feito à medida do desejo, para encontrar um fantasma inconsciente, corpo-objeto destituído da imagem que é erigida sobre a falta fálica.

\section{A imagem do corpo próprio em Lacan}

As primeiras elaborações lacanianas sobre a imagem do corpo estão condensadas, em um primeiro momento de seu ensino ${ }^{6}$, no percurso que começa com o chamado "estádio do espelho" e se desdobra até o "esquema ótico", construção retomada pela última vez em seu Seminário 10, A angústia (1962-1963/2005). A conceituação do estádio do espelho sofre algumas mudanças de acordo com as retificações operadas por Lacan em sua teoria. Como veremos, nos anos 1940 temos a imagem como centro da causalidade psíquica. Nos anos 1950, Lacan vai articular o estádio do espelho às construções relativas ao registro simbólico: aqui o Outro passa a representar o espelho. Para Quinet (1994), nesse momento, Lacan relativiza o estádio do espelho ao submetê-lo ao registro Simbólico, em que a alienação da imagem é substituída pela alienação estrutural ao Outro. Nos anos 1960, Lacan acrescenta como ponto fundamental o olhar como objeto que escapa do Outro materno. O olhar da mãe que observa o sujeito em júbilo diante do espelho situa a experiência especular a partir da pulsão escópica (Quinet, 1994). Buscaremos elucidar esse percurso a partir de pontos recolhidos de acordo com nosso tema, a fim de precisar os contornos da imagem do corpo para Lacan.

6 Existem algumas formas de periodização do ensino de Lacan. Neste artigo, nos orientamos a partir da divisão em primeira e segunda clínicas. Em resumo, a primeira clínica de Lacan é estrutural, em que há uma distinção radical entre neurose, psicose e perversão indicada pela relação do sujeito com o significante do Nome-do-Pai, ou seja, com o simbólico. A segunda clínica, a borromeana, já não se orienta pelo simbólico, ela articula, sem primazia, os três registros - imaginário, real e simbólico - em um nó singular capaz de sustentar a realidade psíquica para cada sujeito. Para os interessados nessa discussão, sugerimos o artigo de Mattos (2009) "A dialética entre a primeira e a segunda clínicas de Lacan".
Em 1949, dentro de uma perspectiva clínica que privilegiava o imaginário, o estádio do espelho é uma construção que fornece esclarecimentos sobre a função do eu na experiência psicanalítica (Lacan 1949/1998). Para Miller (2005), Lacan interpretou o conceito freudiano de narcisismo pelo estádio do espelho. $\mathrm{O}$ conceito de narcisismo tal como Lacan o articulou, nesse momento, dá conta não somente da imagem do corpo próprio, mas do domínio dessa imagem como característica intrínseca ao ser humano. O estádio do espelho organiza um momento inaugural na tenra infância, que se dá entre seis e dezoito meses de vida, cuja função passa por "estabelecer uma relação do organismo com a realidade" (Lacan, 1949/1998, p. 100). Nesse momento, a criança, confrontada com o espelho, é tomada de júbilo ao reconhecer como sua a imagem ali refletida. Lacan parte de um aspecto que chamou comportamental: "o filhote do homem, numa idade em que, por um curto espaço de tempo, mas ainda assim por algum tempo, é superado em inteligência instrumental pelo chipanzé, já reconhece não obstante como tal sua imagem no espelho" (Lacan, 1949/1998, p. 96).

Para Lacan (1949/1998), o estádio do espelho deve ser compreendido como uma identificação, ou seja, "a transformação produzida no sujeito quando ele assume uma imagem" (p. 97). A falta de maturação motora, sua prematuração, conferem a essa experiência fundamental um júbilo. Essa assunção jubilatória da imagem especular manifesta "a matriz simbólica em que o eu se precipita numa forma primordial" (Lacan, 1949/1998, p. 97). Tal forma, continua Lacan, pode ser designada eu-ideal e funcionará como origem das identificações secundárias. O ponto mais importante, destaca o psicanalista, é que esta é a forma que situa a instância do eu em uma discordância de sua própria realidade, afinal, o eu se reconhece pela imagem projetada.

O estádio do espelho compele, a partir da insuficiência, que neste momento do ensino de Lacan é orgânica, a uma identidade alienante. Lacan reconhece que há, a princípio, um momento em que a imagem do corpo ainda não captou o gozo do corpo. É a formação de uma totalidade ortopédica que sucede desde uma imagem despedaçada do corpo que introduz uma nova economia de gozo onde, ancorada na imagem, a libido se torna narcísica. Se quisermos, podemos dizer que é uma primeira organização das pulsões autoeróticas. Aqui Lacan segue Freud (1914/1996) de perto, afinal, para este, o eu não está colocado desde o princípio: o eu precisa ser constituído. Esta constituição necessita de uma "nova ação psíquica", que deve acontecer no cerne da passagem do autoerotismo ao narcisismo. A nova ação psíquica, para Lacan, é a própria antecipação de um corpo unificado, a primeira identificação do sujeito com sua imagem.

Vale ainda acrescentar que, antes da imagem no espelho ser reconhecida como própria, ela é a imagem de outro semelhante. Lacan (1953-1954/1986) nos explica que o estádio do espelho é uma "aventura 
original" onde, pela primeira vez, o infans passa pela experiência de ser visto, refletido e concebido como outro que não ele mesmo. Este dado não é sem consequências, já que:

É esse momento que decisivamente faz todo o saber humano bascular para a mediatização pelo desejo do outro, constituir seus objetos numa equivalência abstrata pela concorrência de outrem, e que faz do eu esse aparelho para o qual qualquer impulso dos instintos será um perigo. (Lacan, 1949/1998, p. 101)

Lacan tira consequências preciosas dessa construção para sua clínica. Ele aponta, fundamentalmente, a importância da imagem do corpo próprio na constituição do eu e de todo psiquismo. Além disso, Lacan nos ensina também sobre o desconhecimento e a alienação do desejo que daí se destacam (Lacan, 1949/1998). No entanto, com o deslocamento de seu ensino, novos parâmetros sobressaem e dão suporte teórico para a construção da imagem do corpo. Com as formulações dos anos 1950, em que há a primazia do Simbólico, o estádio do espelho passa a estar submetido ao Outro e à dialética fálica. $\mathrm{O}$ estádio do espelho, introduzido por Lacan como uma experiência na qual o sujeito, enquanto corpo, se confronta com sua própria imagem, é reconsiderado em função do simbólico, em função da falta de objeto. Como veremos, a imagem de si vem como um substituto dessa falta.

Lacan sustenta (1957-1958/1999) que "o estádio do espelho é o encontro do sujeito com aquilo que é propriamente uma realidade e, ao mesmo tempo, não o é, ou seja, uma imagem virtual" que, no entanto, tem papel decisivo, pois leva o sujeito a uma cristalização, uma Urbild. Nesse momento, a criança cria um campo de apoio no limite da realidade, sua imagem. Esta imagem tem como propriedade ser um sinal cativante que se isola na realidade e, ao mesmo tempo, atrai e captura a libido do sujeito. Lacan (1957-1958/1999) é contundente: "qualquer possibilidade de que a realidade humana se construa passa literalmente por aí" (p. 234). Essa cristalização do eu abre as possibilidades do imaginário e, assim, abre o campo para a criança se identificar com o falo, objeto imaginário, para satisfazer o desejo da mãe. Para Lacan, nesse momento, este é o sentido do júbilo da criança diante do espelho. Assim, o estádio do espelho apresenta um duplo movimento: introduz a forma da imagem do corpo como fundamento essencial do referenciamento do sujeito na realidade, ao passo que essa experiência oferece uma margem em que a criança pode realizar suas primeiras identificações do eu, entrando em uma dimensão simbólica.

No Seminário 6, Lacan (1958-1959/2014) afirma que o sujeito assume sua identidade no campo da linguagem. Aqui, mais uma vez, ele retoma o estádio do espelho em íntima relação com o falo e com o desejo da mãe. Para ele, a parceria do menino com o outro - outro especular que representa sua própria imagem - está justaposta a outra relação sob cuja dependência a relação especular se inscreve. Essa outra relação, mais obscura e ampla, é a da criança com o corpo da mãe. Assim como é necessário, nos diz Lacan (1958-1959/2014), determinada posição em relação ao espelho para que se assuma uma imagem, a criança "só se realiza se se identifica com certa posição de seu ser dentro dos poderes da mãe" (p. 243).

Com efeito, a criança precisa se integrar em um mundo de insígnias dados pelo Outro que situam o $\mathrm{x}$ de seu desejo. Lacan esclarece que esta mãe deve ser entendida como uma primitiva identificação ideal, uma primeira forma do Um. Lacan destaca, nessa construção, que podemos falar, desde a psicanálise, da formação de um Um para o sujeito, mas nunca de uma totalidade, já que o ser humano está sempre dividido. Ou seja, o ser humano é alguém para quem falta algo - "seja macho ou fêmea. é um ser castrado" (Lacan, 1958-1959/2014, p. 244). E é a partir da percepção dessa falta que o sujeito vai buscar, no Outro, o falo como índice de seu desejo, de seu ser.

Nesse sentido, Miller (2005) esclarece que, na identificação tal como proposta por Lacan, o que opera não é somente a imagem, mas um significante escondido em seu interior, o traço unário. Pelo fato de o sujeito ser barrado, falta-lhe uma identidade no significante e, em seu lugar, o sujeito promove i(a), a imagem do corpo próprio e do outro. Assim, a imagem é suportada pelo significante que absorve o imaginário no simbólico. Até este momento de seu ensino, Lacan busca, segundo Miller (2005), reduzir a libido a um significante e ao deslocamento e substituição deste significante. Por esse ângulo, "a razão do imaginário encontra-se no nível da função simbólica, isto é, a falta da identidade significante do sujeito" (Miller, 2005, p. 253).

Nas elaborações precedentes, explica Miller (2005), Lacan tentava reabsorver a libido na ordem simbólica e, assim, reabsorvia o imaginário no simbólico, fazendo do simbólico a verdade do imaginário. Nessa construção, Lacan tratava a libido como unidade, um elemento, o falo. Em seguida, Lacan percebe que essa construção deixa de fora numerosas propriedades da libido freudiana. Assim, o objeto $a$ foi uma necessidade lógica nesta construção. $\mathrm{O}$ falo e o objeto $a$ são duas modalidades da libido freudiana, o primeiro, significante, e o segundo, não-significante. A relação desses dois termos tem como articulação canônica: o " $a$ " como substituto do "-phi" na economia libidinal. Ou seja, há uma castração de gozo - phi à qual se superpõe um suplemento de gozo, o objeto $a$ : a/-phi. Para Miller (2005), "no coração do objeto $a$ existe o -phi da castração, cujo objeto é apenas um envelope" (p. 260). Como resposta à falta - e ao efeito mortificante do significante - surge o elemento de vida, de gozo vivo, o $a$.

Com as formulações sobre o objeto $a$, Lacan inscreverá no estádio do espelho, a partir do que 
chamou agora esquema ótico, o olhar da mãe como fundamental nesta montagem. Para comentá-las, daremos um salto até o Seminário 10 (1962-1963/2005) a fim de destacar, pontualmente, questões importantes para nosso desenvolvimento.

No início desse Seminário sobre a angústia, Lacan diz que tentará articular, mais precisamente, o estádio do espelho e a dimensão significante. Dentro do que já elaborou sobre o tema, Lacan (1962-1963/2005) diz que, na relação especular, o sujeito se constitui em relação ao Outro, e sua marca se forma na relação com o significante. Entretanto Lacan destaca ainda o movimento que a criança faz com a cabeça no momento de júbilo diante do espelho. Basta observar, diz Lacan, a criança vai buscar olhar para quem a segura e garantir seu assentimento. Ou seja, é o olhar da mãe enquanto objeto que garante a imagem do corpo próprio para o sujeito. Este olhar da mãe, objeto evanescente que se inscreve na experiência, mostra outros caminhos teóricos na construção desta etapa primordial na constituição do sujeito. Mas, "quando a relação que se estabelece com a imagem especular é tal que o sujeito fica demasiadamente cativo da imagem para que esse movimento seja possível, é porque a relação dual pura o despoja de sua relação com o Outro" (Lacan, 1962-1963/2005, p. 135). Essa condição se traduz, na clínica da psicose, por um desapossamento da imagem especular, que pode inclusive surgir como duplo.

Nessa construção, Lacan nos mostra que o investimento na imagem especular, situado no interior da dialética do narcisismo, é um tempo fundamental da relação imaginária. E esse tempo "é fundamental por ter um limite. Nem todo investimento libidinal passa pela imagem especular. Há um resto" (Lacan, 1962-1963/2005, pp. 48-49). O resto é o pivô da dialética, função privilegiada sob a forma do falo. Isso significa que, "em tudo o que é demarcação imaginária, o falo virá, a partir daí, sob a forma de uma falta" (Lacan, 1962-1963/2005, p. 49). O falo funciona, sem dúvida, como uma reserva operatória, mas na medida em que não é representado nesse nível imaginário, ele está cortado da imagem especular. A imagem refletida no Outro, caracterizada por uma falta, orienta e polariza o desejo que se relaciona com a ausência. Esta ausência, continua Lacan, é também a possibilidade de uma aparição: o objeto $a$ que pode se instalar nesse lugar. Lacan encontra aqui o terreno da angústia e do estranho ${ }^{7}$. $\mathrm{O}$ estranho freudiano é, para Lacan, aquilo que aparece onde deveria estar - phi. Lacan (1962-1963/2005) acrescenta que "tudo parte da castração imaginária, já que não há imagem da falta ... quando aparece algo ali, a falta vem a faltar" (p. 51).

No Seminário 11, Lacan se distancia do especular para retomar um ponto de vista escópico. Miller (2005)

\footnotetext{
7 Aqui Lacan se refere ao estranho tal como Freud o articulou em seu texto de 1919, "O Estranho". Lacan pondera que o estranho é um eixo fundamental para se abordar a angústia.
}

destaca que "o especular é o privilégio dado à imagem, à forma" (p. 270). Sob a imagem radiante do corpo do outro colocamos i(a), imagem que dissimula, afinal, o horror da castração. Aqui fica clara a função de véu operada pela beleza: a beleza é o véu da castração. Nesse Seminário, Lacan acentua que a prevalência da imagem do corpo próprio é colocada, desde sempre, como uma resposta à falta estrutural. Para Miller (2005) "a prevalência da imagem do corpo no homem, decorre do fato de que ela vem tamponar a falta simbólica da castração" (p. 316). Dessa forma, Lacan pôde afirmar que a consistência do campo visual supõe a metáfora paterna e o Nome-do-Pai. A imagem do corpo próprio sempre traduz a relação do sujeito com a castração, ponto que se torna evidente, por exemplo, quando estamos diante de casos de anorexia ou bulimia e, principalmente, das psicoses. O que nos leva a perceber que essa representação de totalidade que supõe a imagem do corpo próprio tem um avesso. Assim, Miller (2005) aponta que o estádio do espelho vem para suprimir tudo que concerne à percepção da falta e, aqui, o júbilo da criança frente à imagem no espelho só pode ser uma denegação da castração.

A partir do Seminário 11, Lacan pouco falou sobre a imagem do corpo próprio. No entanto, no Seminário 23 (1975-1976/2007) - e nos textos da mesma época -, ao elaborar a noção de sinthome a partir da leitura de James Joyce, ele retoma a discussão. Em seu último ensino, Lacan se interessava por discutir as questões da clínica pela teoria dos nós, na qual são articulados o real, o simbólico e o imaginário. $\mathrm{O}$ corpo será tomado a partir desses três termos. Sucintamente, podemos dizer que o corpo tem seu suporte na imagem, se articula pelas palavras - o corpo é um corpo falado -, e tem seu material real. Ou seja, o corpo é um sintoma.

Nessa época, Lacan nos ensina que o corpo não é algo que se é, mas algo que se crê possuir (Lacan, 1975). Consequentemente, podemos dizer que um corpo, sendo da ordem da crença, está sujeito à dúvida ou à descrença, e até mesmo à certeza delirante que este corpo é possuído por outro, como nos delírios de influência da psicose. Assim, o corpo precisa ser subjetivado, ou corre-se o risco de que o sujeito permaneça despossuído de seu suporte imaginário e da consistência que tal suporte proporciona a cada um (Frederico \& Bastos, 2008).

Em 1975, na Conferência de Genebra sobre o sintoma, Jacques Lacan (1975b) enfatiza que "o homem está capturado pela imagem do seu corpo” (p. 3). Para chegar a essa conclusão, ele parte da concepção de que o pensamento é, afinal, um engodo: "um engodo em algo que especifiquei com o que chamo imaginário" (Lacan, 1975b, p. 3). Se o homem não tivesse um corpo, ressalta Lacan, não só não pensaria, mas também não estaria profundamente capturado por sua imagem. Isso merece ênfase, já que explica o privilégio da imagem para o ser falante. 
Seu mundo, se é que esta palavra tem algum sentido, seu Unwelt, o que o rodeia, ele o corpo-reifica, o faz coisa à imagem de seu corpo. Não tem a menor ideia, certamente, do que acontece neste corpo. Como sobrevive um corpo? ... O corpo ganha seu peso pela via do olhar. (Lacan, 1975b, p. 3)

Com efeito, o imaginário se define, neste texto, para Lacan (1975b), como uma forma, ou "uma aparência adorada pelos homens" (p. 3). Ele diz ainda que a superfície do corpo é o lugar de onde o homem tirou a ideia de uma forma privilegiada, e dessa ideia surge o conceito de mundo e de esfera. Também em 1975, nas Conferências e entrevistas nas universidades norteamericanas, Lacan (1975a) acrescenta que o narcisismo freudiano é o nó fundamental que funciona para que o homem tenha uma imagem do mundo como unidade de pura forma, e esta noção de unidade começa pelo corpo. O narcisismo é, então, um nó fundamental, porque, para Lacan, é da superfície do corpo "que o homem tomou a ideia de uma forma privilegiada, e sua primeira apreensão do mundo foi a apreensão do seu semelhante" (Lacan, 1975a, p. 31). O imaginário é entendido então como suporte, a figura que carrega um material real, o corpo. Lacan diz ainda: "o real não é o mundo exterior, ele é também a anatomia, isso tem a ver com o corpo todo" (Lacan, 1975b, p. 40).

O que tornaria a imagem algo tão fascinante? Para Frederico e Bastos (2008), a imagem cativa o ser falante na medida em que ela é capaz de recobrir, exatamente, a falta fálica quando a castração é simbolizada. $\mathrm{O}$ eu, desde Freud (1923/1996), é uma superfície constituída a partir uma unidade narcísica que, como nos ensinou Lacan ao conceituar o estádio do espelho, dá lugar a uma experiência de júbilo diante do desamparo cravado na imaturidade motora e na fragmentação corporal do bebê humano. Assim, como vimos, no engodo da identificação com sua imagem, o eu ganha uma armadura de totalidade ortopédica de uma identidade alienante que "marcará com sua estrutura rígida todo o seu desenvolvimento mental" (Lacan, 1949/1998, p. 100).

No entanto vimos também, nas elaborações lacanianas, que a consistência que mantém junto e organizada a unidade corporal não é dada somente pelo imaginário. Esta unidade depende ainda do simbólico, já que é uma marca vinda do campo do Outro que possibilita ao ser falante ter um corpo. Tal marca é a incidência de um significante, de um nome - o Nome-do-Pai (Frederico \& Bastos, 2008).

Em 1976, no Seminário 23, O sinthoma, Lacan destaca a relação do escritor James Joyce com seu corpo. Joyce testemunha, em Retrato de um artista enquanto jovem, uma surra que levou de alguns colegas na saída escola. Joyce diz que não guardou rancor, que toda história se esvaiu "como uma casca" (Lacan, 1975-1976/2007, p. 145). Lacan diz que o escritor, por esta via, metaforiza sua relação com seu próprio corpo. Ou seja, na surra, o corpo de Joyce se solta como uma casca, e é por essa razão que ele não guarda nenhum afeto quanto à violência sofrida. Lacan retira uma consequência importante dessa passagem: "Se o ego é dito narcísico, é porque, em certo nível, há alguma coisa que suporta o corpo como imagem" (Lacan, 1976/2007, p. 146).

Para elucidar esse ponto, vale lembrar uma apresentação de paciente conduzida por Lacan também em 1976, Mlle. B. Ao longo da entrevista, Mlle B., na busca de imagem que estabeleça uma consistência e unidade para seu corpo, descreve alguns personagens que tenta imitar, se identificar, entretanto uma identificação estável parece impossível. Em uma metonímia incessante de identificações - metonímia reproduzida em sua fala, na qual as palavras se esvaem, mudam de sentido várias vezes em uma mesma frase sem alcançar um significado a paciente mostra a falta de consistência em que vive: não se reconhece em nenhuma identificação e não tem acesso ao reconhecimento vindo do Outro. Ela diz que gosta de "viver suspensa como uma roupa" e que se vê como um teatro de marionetes (Lacan, 1976, p. 20). Lacan sublinha, na entrevista, que Mlle. B. não tem a menor ideia que possui um corpo para vestir, afinal "não há ninguém para habitar a vestimenta. Ela é este pano" (Lacan, 1976, p. 30). Ou seja, sem a vestimenta do imaginário, o sujeito fica à deriva, sem um corpo para habitar.

Assim, a imagem funciona, enfim, como uma vestimenta para os objetos pulsionais. Quando isso não opera, quando o imaginário fica solto do nó que o articula aos registros simbólico e imaginário, o corpo permanece fragmentado, na desordem dos objetos $a$. Na obra de Hans Bellmer, encontramos esse corpo desvelado. O que a obra do artista nos mostra é que, sem essa imagem, totalizadora e siderante, o que resta é um corpo informe, permitindonos revisitar conceitos caros à clínica psicanalítica como corpo e representação corporal.

\section{Algumas conclusões sobre a arte de Hans Bellmer e a representação do corpo}

A Pequena anatomia da imagem de Hans Bellmer nos fala da não coincidência entre corpo e imagem do corpo tão repetidamente elucidada na clínica - por exemplo, nas conversões histéricas, na anorexia ou na língua de órgãos esquizofrênica. No ensaio, o artista deixa claro que um corpo se faz também com o gozo, sendo, cada corpo, uma superfície erógena singular. Bellmer desconstrói a imagem para ter acesso a um corpo fantasmático, mostrando que toda representação do corpo como imagem nunca é dada a priori, ela é construída a partir do corpo fragmentado. A imagem do corpo é uma operação de velamento do objeto pela imagem.

Retomando o argumento de Miller que orienta esta discussão, o segredo da imagem é a castração, já que a operação de corte suposta por ela é capaz de velar o horror do real. Podemos aqui evocar as esculturas do corpo masculino feitas por artistas nazistas ${ }^{8}$ que exaltam a boa forma trazendo

8 Conferir, por exemplo, a escultura Prontidão, de 1939, feita pelo escultor preferido por Hitler, Arno Breker. 
em seu bojo um corpo humano idealizado, sem fissuras ou frestas, para, em contrapartida, observarmos o corpo revelado por Bellmer, um avesso. As primeiras, imagens da perfeição em um corpo masculino, dissimulam, velam a castração, são imagens de um corpo ideal, e podemos dizer que mostram um corpo inviolável, fortificado. As imagens de Bellmer, corpos femininos, hermafroditas ou sem sexo, mostram um corpo desorganizado, sem a arquitetura apaziguante da imagem fálica.
A imagem supõe, portanto, o corpo como forma unificada. As imagens apresentadas por Bellmer deixam ver o corpo enquanto objeto, não falicizado, sem o véu que a castração coloca ao real anatômico. O trabalho do artista testemunha a existência de um corpo sem imagem, ou seja, o corpo despedaçado, e nos ensina que diante da ausência dessa imagem, o corpo fica à mercê de um puro real. Nesse movimento, o que fica descoberto é um gozo sem limites, um corpo sem imagem, uma forma sem ideal.

\section{Hans Bellmer and your little anatomy of the image: own body and psychoanalysis}

Abstract: In Petite Anatomie de l'image (1949), Hans Bellmer, an artist, describes a body image theory that assumes human anatomy to be subjective, imagined, and even permeated by psychopathological states. Thus, Bellmer shows an inner body designed by memory traces and purely mental image, that is, he introduces an instinctual body. Based on his work, we analyze what artists can teach lacanian psychoanalysis regarding one's own body and its representation, as they are important concepts for work in the clinic. Thus, a valuable indication guides this discussion: the secret of image is castration.

Keywords: image, own body, enjoyment, castration.

\section{Hans Bellmer et sa petite anatomie de l'image : propre corps et psychanalyse}

Résumé : Dans Petite Anatomie de l'image (1949), l'artiste Hans Bellmer formule une théorie de l'image du corps partant du principe que l'anatomie humaine est subjective, imaginaire, et même imprégnée d'états psychopathologiques. Ainsi, Bellmer montre un corps interne, dessiné par des traces de mémoire et par une image purement psychique, c'est-à-dire qu'il met le corps pulsionnel dans la scène. Devant cet oeuvre, nous demandons ce que l'artiste enseigne au psychanalyste lacanien sur le corps et sa représentation, de concepts importants pour la clinique. L'affirmation suivante guidera notre discussion : le secret de l'image est la castration.

Mots-clés : image, propre corps, joissence, castration.

\section{Hans Bellmer y su pequeña anatomía de la imagen: cuerpo propio y psicoanálisis}

Resumen: En Petite Anatomie de l'image (1949), el artista Hans Bellmer plantea una teoría de la imagen del cuerpo, que parte de la premisa de que la anatomía humana es subjetiva, imaginaria e incluso permeada por estados psicopatológicos. Así Bellmer muestra un cuerpo interno, dibujado por rasgos de memoria y por una imagen puramente psíquica, es decir, pone en escena el cuerpo pulsional. Con base en esta obra, nos preguntamos qué enseña el artista al psicoanálisis lacaniano en cuanto al cuerpo propio y su representación, conceptos importantes para la clínica. En este sentido, una valiosa indicación orientará esta discusión: el secreto de la imagen es la castración.

Palabras clave: imagen, cuerpo propio, gozo, castración

\section{Referências}

Bataille, G. (1929). Oeil. In G. Bataille (Org.), Documents (pp. 216-220) Paris: Gallica.

Bellmer, H. (2002). Petite Anatomie de l'image. Paris: Editions Allia. (Trabalho original publicado em 1949)

Brousse, M-H. (2001). El cuerpo en psiocanalisis. Madrid: Saor.

Didi-Huberman, G. (2002). Visual experience, form and symptom according to Carl Eistein. Papers of Surrealism, (7), 1-25.
Eistein, C. (1991). Rossignol. In C. Einstein, Documents (pp. 177-118). Paris: Gallica. (Trabalho original publicado em 1929)

Foster, H. (2008). Belleza compulsiva. Madrid: Adriana Hidalgo.

Frederico, C., \& Bastos, A. (2008). Um sujeito à procura da imagem: o caso Mlle B. Estilos da Clínica, 13(25), 180-191.

Freud, S. (1996). Sobre o narcisismo: uma introdução. In Edição standard brasileira das obras psicológicas 
completas de Sigmund Freud (J. Salomão, trad., Vol. 14, pp. 77-81). Rio de Janeiro, RJ: Imago. (Trabalho original publicado em 1914)

Freud, S. (1996). O ego e o id. In Edição standard brasileira das obras psicológicas completas de Sigmund Freud (J. Salomão, trad., Vol. 19, pp. 25-77). Rio de Janeiro, RJ: Imago. (Trabalho original publicado em 1923)

Gonzalez, O. (2007). Hans Bellmer: la estética de la perversión. Agulha: Revista de Cultura, (60). Recuperado de https://bit.ly/31MYXcO

Lacan, J. (1975a). Conférences et entretiens dans des universités nord-américaines, 1976. Recuperado de https://bit.ly/2PSafqo

Lacan, J. (1975b). Conferência de Genebra sobre o sintoma. Recuperado de https://bit.ly/3iBRmV9

Lacan, J. (1976). Presentación del viernes 9 de abril de 1976. Caso Brigitte: 27 años Enfermedad de la mentalidad. In 8 presentaciones de enfermos em Sainte-Anne. San Sebastián: Federación de Foros del Campo Lacaniano.

Lacan, J. (1986). O seminário, livro 1: os escritos técnicos de Freud, 1953-1954. Rio de Janeiro, RJ: Zahar.

Lacan. J. (1998). O estádio do espelho como formador do eu. In Escritos (V. Ribeiro, trad., pp. 96-103). Rio de Janeiro, RJ: Zahar. (Trabalho original publicado em 1949)

Lacan, J. (1998). O seminário, livro 11: os quatro conceitos fundamentais da psicanálise, 1964. Rio de Janeiro, RJ: Zahar.

Lacan, J. (1999). O seminário, livro 5: as formações do inconsciente, 1957-1958. Rio de Janeiro, RJ: Zahar.

Lacan, J. (2005). O seminário, livro 10: a angústia, 19621963. Rio de Janeiro, RJ: Zahar.
Lacan, J. (2007). O seminário, livro 23: o sinthoma, 1975-1976. Rio de Janeiro, RJ: Zahar.

Lacan, J. (2014). El seminario, libro 6: el deseo y su interpretación, 1958-1959. Buenos Aires: Paidós.

Marcos, C. M. (2015). Da escrita ao objeto ou a escrita da voz. In L. C. Teixeira (Org.), A psicanálise nas searas da universidade, do direito, da arte e da literatura (pp. 133-145). Belo Horizonte, MG: CRV.

Masson, C. (2000). La fabrique de la poupée chez Hans Bellmer. Paris : L'Harmattan.

Mattos, C. P. A dialética entre a primeira e a segunda clínicas de Lacan. Almanaque, (5), 1-11. Recuperado de https://bit.ly/2FdU2d5

Miller, J.-A. (2005) Silet: os paradoxos da pulsão de Freud a Lacan. Rio de Janeiro, RJ: Zahar.

Quinet, A. (1994). A imagem rainha ou a boneca barroca. Opção Lacaniana, (11), 46-50.

Riguini, R. D. (2015). O olho obsceno: considerações sobre o objeto olhar em Georges Bataille e Jacques Lacan (Tese de doutorado). Pontifícia Universidade Católica de Minas Gerais, Belo Horizonte, MG.

Surya, M. (2002). Georges Bataille: an intellectual biography. London: Verso.

Wajcman, G. (1984). Narcisse ou le fantasme de la peinture. In M. Gagnebin \& C. Wiart (Orgs.), L'or d'Atalante: Art et fantasme (pp. 107-126.). Seyssel: Champ Vallon.

Webb, P., \& Short, R. (2004). Death, desire and the doll: the life and art of Hans Bellmer. New York: Solar Books.

Recebido: 09/03/2018

Revisado: 04/09/2019

Aprovado: 03/08/2020 